${ }^{1}$ BDS, FMCDS. Department of Child Dental Health, Obafemi Awolowo University Teaching Hospitals Complex, Ile-Ife, Nigeria.

${ }^{2}$ BchD, FWACS. Department of Child Dental Health, Obafemi Awolowo University, Ile-Ife, Nigeria.

${ }^{3}$ MB.ChB, FMCR. . Department of Radiology, Obafemi Awolowo University, Ile-Ife, Nigeria.
Corresponding author: Dr Olabimpe Abigail Soyoye Department of Child Dental Health, Obafemi Awolowo University Teaching Hospitals Complex, Ile-Ife, Nigeria.

Phone - +2347031010372,

E-mail: bimpe211@yahoo.com

Received: May 31, 2017

Accepted: August 14, 2017

\section{Relationship between} masseter muscle thickness and overbite values in a Nigerian population

\author{
Olabimpe Abigail Soyoye ${ }^{1}$, Otuyemi Donald \\ Olayinka², Kolawole Kikelomo Adebanke², \\ Ayoola Oluwagbemiga Oluwole ${ }^{3}$
}

Objective: This study determined the relationship between masseter muscle thickness and overbite values among Nigerians. Methods: The subjects included 66 consecutive patients (21 males and 45 females) who presented for fixed orthodontic appliance treatment. Overbite values were measured from standard lateral cephalometric radiographs taken for all patients, who were thereafter divided into three groups of reduced overbite $(\mathrm{n}=22$, mean $-1.11+2.18 \mathrm{~mm})$, normal overbite $(n=22$, mean $2.59+0.50 \mathrm{~mm})$ and increased overbite $(n=22$, mean $5.21+1.39 \mathrm{~mm}$ ). The masseter muscle thickness of each patient was measured bilaterally using ultrasonography. Associations between masseter muscle thickness and different overbite values were analyzed using unpaired t-test, ANOVA and Tukey's multiple comparison analysis. Results: Mean masseter muscle thickness was $11.23 \pm 2.40 \mathrm{~mm}$ during relaxation and $12.81 \pm 2.64 \mathrm{~mm}$ during contraction for study participants. The masseter muscle on the habitual side of mastication of participants was generally thicker but the difference was not statistically significant $(P>0.05)$. There was a progressive increase in masseter muscle thickness from reduced overbite through normal overbite to increased overbite groups and the differences were statistically significant $(P<0.01)$. Tukey's multiple comparisons showed significant differences between all the three overbite groups $(P<0.05)$. Conclusion: There was a direct relationship between the muscle thickness and overbite variations.

Keywords: Masseter muscle thickness. Overbite values. Nigerian population. 


\section{Introduction}

The practice of contemporary orthodontics involves the understanding and application of many biomechanical principles that enable the orthodontist achieve a desired outcome. Orthodontists have developed many techniques based on these principles to effect favourable changes in the dento-facial complex. Treatment planning in orthodontics is, however not based entirely on biomechanical considerations, but also requires adequate knowledge of the craniofacial and muscular environment of each patient ${ }^{1,2}$. Muscles of mastication that derive their origin or insertion from the maxilla and mandible, especially the masseter muscle contribute to craniofacial growth, and are of paramount importance in the aetiology of malocclusion as well as stability of orthodontic treatment ${ }^{3-5}$.

The masticatory muscles, including the masseter muscle, affect craniofacial growth in two major ways; first, the formation of bone at the point of muscle attachment depends on the activity of the muscles, secondly the musculature is an important part of the total soft tissue mass whose growth normally carries the jaws downward and forward. Loss of part of the musculature from any cause often results in underdevelopment of that part of the face. Excessive muscle contraction also causes growth restriction on the affected part of the face, thus producing facial asymmetry ${ }^{6}$. On the other hand, a major decrease in the muscle tonicity as seen in muscular dystrophy, cerebral palsy and muscle weakness syndromes, allows the mandible to drop downward away from the rest of the facial skeleton, resulting in increased anterior facial height, distortion of facial proportion and mandibular form, excessive eruption of the posterior teeth, narrowing of the maxillary arch and an anterior open bite ${ }^{7}$.

For normal vertical growth and development, growth in the anterior part of the face must be proportional to that occurring in the posterior segment. In the absence of this, a relative growth rotation of the mandible can develop. Should growth in the posterior part of the face exceed that occurring anteriorly, then the net effect is an anterior, forward closing rotation of the mandible producing the typical short face deformity and deep overbite associated with the short face syndrome ${ }^{8-10}$. Conversely, reduction in growth in the posterior part of the face in comparison with what occurs in the anterior segment results in an opening or clockwise rotation of the mandible with the net effect being an excessive anterior facial height. This frequently leads to an anterior open bite with associated long face deformity.

The masseter muscle thickness can be assessed by various imaging techniques including ultrasound scanning, computed tomography (CT) and magnetic resonance imaging (MRI). CT was used by Weijs and Hillen ${ }^{11}$ to measure masticatory muscle thickness in adults and they reported that the masseter and medial pterygoid muscles were thicker in persons with short faces and a small jaw angle. MRI was used by Hannam and Wood ${ }^{12}$ who found a correlation between the cross section of masseter and bizygomatic width in 22 adult males.

Ultrasonography [US] has been used by a number of investigators to assess masseter muscle thickness. US is a non invasive imaging technique of assessing the parameters of the masticatory muscle and has the advantage over CT and MRI of being relatively 
inexpensive, reproducible, less complicated to use and with no known cumulative biological effect ${ }^{13}$. Ultrasonography is an indicated technique for evaluating muscles in vivo, for longitudinal studies and for evaluation in children since its advantages outweigh the disadvantages ${ }^{13}$. Moreover, it adds more valuable information to that found by conventional methods for the study of muscles of mastication and other muscles and organs of the human body. In addition, it is readily accepted by patients and their parents. Raadsheer et al. ${ }^{14}$, compared results of measurement of mid-belly masseter muscle thickness using US and MRI and showed US to be an accurate and reproducible imaging technique. However, US is not without its attendant limitations, it has lagged behind the other imaging techniques i.e. CT and MRI in establishing practical three dimensional (3D) visualisation due to problems associated with acquiring and displaying 3D sets data ${ }^{15}$.

Abnormalities in the vertical dimensions, whether in children or adults present the greatest difficulties during active treatment and maintenance of treatment outcome due to the strong influence of the masticatory muscles ${ }^{8}$. Therefore, the aims of this study were to determine the masseter muscle thickness among a group of Nigerians using ultrasonography, as well as to relate masseter muscle thickness to their different overbite values.

\section{Materials and method}

This research was approved by the research ethics committee of the hospital; protocol number ERC/2013/07/16. The sample size was determined by utilizing the formula for calculating sample size for comparative research ${ }^{16}$ study. Sixty-six participants (45 females and 21 males) who presented for fixed orthodontic appliance therapy participated in the study. The participants were informed about the objectives, risks and benefits, the voluntary nature of participation and freedom to withdraw from the study. Written informed consent was thereafter obtained from each willing participants. For those younger than 18years, parental consent was obtained including the child's assent. Participants in this study experienced no direct benefit and no compensation was paid to them. The selection criteria used were participants aged 12 to 30 years who presented at the orthodontic clinic of the hospital with malocclusion, no previous history of orthodontic treatment or orthognathic surgery and participants who gave their consent. Exclusion criteria applied were participants with marked jaw asymmetry or craniofacial disorders and those with congenital developmental anomalies of the lips, mouth or face.

The participants, having met the inclusion criteria were consecutively allotted into three groups of equal number based on their overbite values : reduced overbite (overbite less than $2 \mathrm{~mm}$ ), normal overbite (overbite between $2-3 \mathrm{~mm}$ ) and increased overbite (overbite greater than $3 \mathrm{~mm})^{17}$. The overbite was measured as the vertical overlap of the upper and lower incisors. The masseter muscle thickness was measured using ultrasonography at the Department of Radiology of the hospital by one of the authors (AOO). The thickness of the masseter muscle was measured using a real time MINDRAY DC-7 ultrasound machine with a $7.5 \mathrm{MHz}$ linear probe.

Bilateral measurements were made with the subjects in supine position and their heads turned side-ways as described by Kiliaridis and Kalebo ${ }^{18}$, that is, the angle of the probe during scanning was adjusted to produce the strongest echo from the mandibular 
ramus, achieved when the scan plane is perpendicular to its surface. Imaging and measurements were performed three times, with an interval of five minutes between each measurement. The intra-observer reliability coefficient was calculated for the three repeated measurements and was found to be 0.94 . All measurements were made by the same operator (AOO) to eliminate inter-observer error.

In order to register the scan plane at right angle to the long axis of the muscle, the probe was oriented at an estimated angle of 30 degrees to the Frankfort plane. The orientation of the probe was maintained manually, while the full length of the muscle was scanned from origin to insertion. The site of measurement was in the thickest part of the masseter muscle close to the level of the occlusal plane, halfway between the zygomatic arch and the gonial angle, approximately in the middle of the mediolateral distance of the ramus.

Imaging and measurements for each individual were performed twice for the masseter muscle; during relaxation and during maximal clenching. In the relaxed state, the participants were asked to maintain slight inter-occlusal contacts in order to avoid muscle stretching as a result of the mouth opening. In the contracted state, the participants were asked to clench maximally in the intercuspal position. The measurements were made directly from the image at the time of scanning and all the distances were read to the nearest $0.1 \mathrm{~mm}$. In addition, information was obtained from the participants with regards to the habitual side of mastication after measurements.

\section{Statistical method}

SPSS version 20 was used for data entry and analysis. Analysis of Variance (ANOVA) test was used to determine the relationship between the masseter muscle thickness and overbite values. Tukey' multiple comparison analysis was used to assess the relationship between the masseter muscle thickness and the different overbite groups. The level of significance was set at $\mathrm{P}<0.05$.

\section{Results}

A total of 66 subjects who fulfilled the inclusion criteria were recruited into the study. This consisted of 21 males (31.82\%) and 45 (68.18\%) females. The participants' ages ranged from 12 to 30 years with a mean age and standard deviation of $19.15 \pm 4.73$ years. Mean age and standard deviation of male participants was $19.90 \pm 5.35$ years and that of the females was $18.80 \pm 4.43$ years, with no statistically significant gender difference $(p=0.416)$ (Table 1).

Table 1. Characteristics of participants according to gender

\begin{tabular}{lcc}
\hline Characteristics of participants & Male & Female \\
\hline Distribution of sample according to number (\%) & $21(31.8 \%)$ & $45(68.2 \%)$ \\
\hline Age mean \pm SD (years) & $19.90 \pm 5.35$ & $18.80 \pm 4.43$ \\
\hline Median age (years) & 20 & 18 \\
\hline Age range (years) & $13-29$ & $12-30$ \\
\hline Occlusal vertical dimension (overbite) & & \\
\hline Reduced (-1.11+2.18mm) & $8(36.4 \%)$ & $14(63.6 \%)$ \\
\hline$\quad$ Normal overbite $(2.59+0.50 \mathrm{~mm})$ & $9(40.9 \%)$ & $13(59.1 \%)$ \\
\hline Increased overbite $(5.21+1.39 \mathrm{~mm})$ & $4(18.2 \%)$ & $18(81.8 \%)$ \\
\hline
\end{tabular}


The masseter muscle thickness was greater during contraction ( mean - $12.81 \pm 2.64$ ) than the relaxation phase ( mean $-11.23 \pm 2.40$ ), although the difference was not statistically significant. The muscle thickness was greater on the right side both during relaxation and contraction phases among the study participants. There was no statistically significant difference in the muscle thickness among both gender. $(p>0.05)$ (Table 2).

Table 2. Gender distribution of masseter muscle thickness during relaxation and Contraction phases

\begin{tabular}{lcccc}
\hline Characteristics of participants & Male $(\mathbf{n}=\mathbf{2 1})$ & Female $(\mathbf{n}=\mathbf{4 5})$ & Total $(\mathbf{N}=\mathbf{6 6})$ & $\mathbf{p}$ value \\
\hline Right masseter muscle relaxation & $11.35 \pm 2.30$ & $11.58 \pm 2.65$ & $11.51 \pm 2.52$ & 0.726 \\
\hline Left masseter muscle relaxation & $10.85 \pm 2.42$ & $11.00 \pm 2.74$ & $10.95 \pm 2.63$ & 0.826 \\
\hline Right masseter muscle contraction & $13.47 \pm 2.74$ & $13.22 \pm 2.94$ & $13.30 \pm 2.86$ & 0.744 \\
\hline Left masseter muscle contraction & $12.28 \pm 3.02$ & $12.32 \pm 2.75$ & $12.31 \pm 2.82$ & 0.954 \\
\hline Mean masseter muscle relaxation & $11.10 \pm 2.17$ & $11.29 \pm 2.53$ & $11.23 \pm 2.40$ & 0.761 \\
\hline Mean masseter muscle contraction & $12.88 \pm 2.70$ & $12.77 \pm 2.64$ & $12.81 \pm 2.64$ & 0.884 \\
\hline
\end{tabular}

A large number of the participants (91\%) were found to masticate on the right. The masseter muscle was generally thicker on the habitual side of mastication but the differences was not statistically significant $(p>0.05)$ (Table 3).

Table 4 shows Two-way ANOVA of muscle thickness in relation to different occlusal vertical dimensions (overbite). In the entire study population, there was a progressive increase in the muscle thickness across the groups from reduced overbite through normal overbite to increased overbite during both relaxation and contraction. These differences were statistically significant.

Table 3. Distribution of masseter muscle thickness according to the habitual side of mastication

\begin{tabular}{lccc}
\hline & \multicolumn{3}{c}{ Side of mastication } \\
\hline Right masseter muscle relaxation & $\begin{array}{c}\text { Right }(\mathrm{n}=\mathbf{5 9}) \\
\text { Mean } \pm \text { SD }\end{array}$ & $\begin{array}{c}\text { Left }(\mathbf{n}=\mathbf{6}) \\
\text { Mean } \pm \text { SD }\end{array}$ & p value \\
\hline Left masseter muscle relaxation & $11.64 \pm 2.49$ & $10.03 \pm 2.79$ & 0.141 \\
\hline Right masseter muscle contraction & $10.86 \pm 2.63$ & $11.20 \pm 2.58$ & 0.767 \\
\hline Left masseter muscle contraction & $13.45 \pm 2.82$ & $11.27 \pm 2.56$ & 0.073 \\
\hline
\end{tabular}

Table 4. Two-way ANOVA of muscle thickness in relation to occlusal vertical dimensions (overbite)

\begin{tabular}{llcccc}
\hline $\begin{array}{l}\text { Masseter muscle } \\
\text { status }\end{array}$ & \multicolumn{1}{c}{ Sex } & $\begin{array}{c}\text { Normal } \\
\text { overbite }(\mathbf{n = 2 2})\end{array}$ & $\begin{array}{c}\text { Increased } \\
\text { overbite }(\mathbf{n = 2 2})\end{array}$ & $\mathrm{F}^{2}$ & p value \\
\hline Relaxation & Male & $9.81 \pm 1.54$ & $10.90 \pm 1.70$ & 10.37 & $0.001^{*}$ \\
& Female & $10.00 \pm 2.34$ & $11.60 \pm 1.86$ & 3.05 & 0.058 \\
& Total & $9.93 \pm 2.05$ & $11.32 \pm 1.79$ & 11.52 & $0.002^{*}$ \\
\hline Contraction & Male & $11.26 \pm 1.62$ & $16.71 \pm 2.65$ & 11.01 & $0.001^{*}$ \\
& Female & $11.15 \pm 2.23$ & $13.91 \pm 2.58$ & 5.22 & $0.009^{*}$ \\
& Total & $11.19 \pm 1.99$ & $14.42 \pm 2.76$ & 10.76 & $0.001^{*}$ \\
\hline
\end{tabular}

*statiscally significant 
Comparison of masseter muscle thickness in the different occlusal vertical dimensions using Tukey's multiple comparison analysis showed a statistically significant difference in the muscle thickness between the reduced and normal overbite groups both during relaxation and contraction $(P<0.05)$. Similarly, there was a highly statistically significant difference in the muscle thickness between the reduced and increased overbite group both under relaxation and contraction $(p<0.01)$. A statistically significant difference was attained only during contraction between the normal and increase overbite groups (Table 5).

Table 5. Comparison of masseter muscle thickness in different occlusal vertical dimensions using Tukey's multiple comparison analysis

\begin{tabular}{lcc}
\hline \multirow{2}{*}{ Comparison of overbirte values } & \multicolumn{2}{c}{ Masseter muscle state } \\
\cline { 2 - 3 } & Relaxation & Contraction \\
\hline Reduced overbite/Normal overbite & P-value & P-value \\
\hline Increased overbite/Normal overbite & $0.021^{*}$ & $0.012^{*}$ \\
\hline Reduced overbite/Increased overbite & 0.107 & $0.035^{*}$ \\
\hline${ }^{*}$ statiscally significant & $0.001^{*}$ & $0.001^{*}$ \\
\hline
\end{tabular}

*statiscally significant

\section{Discussion}

The active functional and resting forces of the masticatory muscles particularly the masseter muscle, are responsible for the integrity of the dental arches and relation of the teeth to each other. Any aberration of these muscles either in terms of size, thickness or function will affect the integrity of the dental and skeletal structures or cause malocclusion.

The mean masseter muscle thickness during relaxation and contraction phases in this study are lower than those reported from previous studies from the Nigerian, Turkish and Japanese populations. The previous Nigerian study by Egwu et al. ${ }^{19}$ reported a higher mean thickness. This may be due to ethnic and/or environmental differences as the sample population of the earlier work was amongst the Igbo extraction (south-eastern Nigeria), well known for their built and physique unlike this present study carried out amongst the population in the South western Nigeria (Yoruba ethnic group) with less built.

Satiroglu et al. ${ }^{20}$ and Kubota et al. ${ }^{21}$ reported higher mean thickness for Turkish and Japanese population respectively. However, this study recorded higher values than the values reported by Benington et al. ${ }^{15}$ for a British population. These variations in thickness of the masseter muscle across the different populations may be associated with racial differences and the relative indulgence in masticatory activities, possibly from different diet that may have led to the attendant adaptive variation in size. It may also be associated with the orientation and size of the muscle fibres which may have genetic and environmental backdrop ${ }^{19}$. The higher values obtained during contraction of the muscle compared to relaxation in this study is consistent with those of previous studies by Egwu et al. ${ }^{19}$, Satiroglu et al. ${ }^{20}$ and Kubota et al. ${ }^{21}$ This disparity between the values in masseter muscle thickness during relaxation and during maximal clenching 
(i.e contraction) can be explained by the fact that during the contraction phase, as the mandible is elevated, there is enlargement and thickening of the muscle fibres which may account for the observed higher thickness in the clenched state.

The right masseter muscle was thicker than that of the left both during relaxation and contraction in all the participants. This finding is consistent with the findings of Chan et al. ${ }^{4}$, Satiroglu et al. $^{20}$ and Rani and Ravi ${ }^{22}$ who reported that the right massetter muscle was much thicker than the left side. A possible explanation may be due to the fact that most of the participants in this study masticated more on the right side of their mouth which may amount to exercising the right masseter muscle more than the left. Exercising the muscle has been known to increase its thickness and the bite force, and a significant positive correlation has been found between bite force magnitude and the ultrasound thickness of the masseter muscle $e^{5,23,24}$. This is also supported by previous studies of $\mathrm{He}$ et al. ${ }^{25}$ and Kiliaridis et al. ${ }^{26}$ who reported that reduced activity of the masseter muscle resulted in thin muscle fibres. However, a previous study by Raadsheer et al. ${ }^{24}$ in 1999 reported greater thickness on the left side, whereas Raadsheer et al. ${ }^{5}$ and Marquezin et al. ${ }^{27}$ found no side differences in the thickness of the muscle in subjects with normal occlusion.

Of the three study groups considered in this study, participants in the increased overbite group had the highest masseter muscle thickness, followed by the normal overbite group with the reduced overbite group demonstrating the least thickness, both during the relaxation and contraction phases of the muscle. This is in agreement with the studies of by Satiroglu et al. ${ }^{20}$, Pereira et al. ${ }^{28}$ and van Spronsen et al. ${ }^{29}$ who reported that individuals with increase (deep) overbite tend to have thicker masseter muscle. Rasheed et al. ${ }^{30}$ in their study of electromyographic and ultrasonographic evaluation of the circum-oral musculature also found that deep-bite subjects demonstrated greater thickness of masseter muscle compared with normal and open bite subjects.

A possible explanation for the higher value of masseter muscle thickness recorded in subjects with increased or deep overbite and a thinner result recorded in the reduced overbite group in this study may be due to the fact that individuals with deep overbite tend to have short face while those with reduced overbite or an anterior open bite tend to demonstrate a long face morphology. This is consistent with the results of previous studies by Weijs and Hillen ${ }^{11}$, Benington et al. ${ }^{15}$, Kiliaridis and Kalebo ${ }^{18}$, and Satiroglu et al ${ }^{20}$ which showed that the masseter muscle is thicker in individuals with short face who tend to have deep overbite, and thinner in those with long face who tend to have reduced overbite or an anterior open bite.

Another possible reason for the greater thickness recorded for the deep bite and the smaller thickness for the reduced overbite subjects may be because the type II muscle fibers are present in greater numbers in these patients than those seen in normal and reduced overbite subjects. In contrast, patients with reduced overbite demonstrate not only a reduced number of type II fibers, but these fibers are also smaller in size $^{31}$. Also, reduced overbite subjects tend to have thinner masseter muscle because the superficial masseter muscle is anteriorly inclined and obliquely oriented relative to the occlusal plane and has a superior positioning of its insertion on the mandible compared to deep overbite individuals who have vertically oriented masseter muscle ${ }^{3}$. 


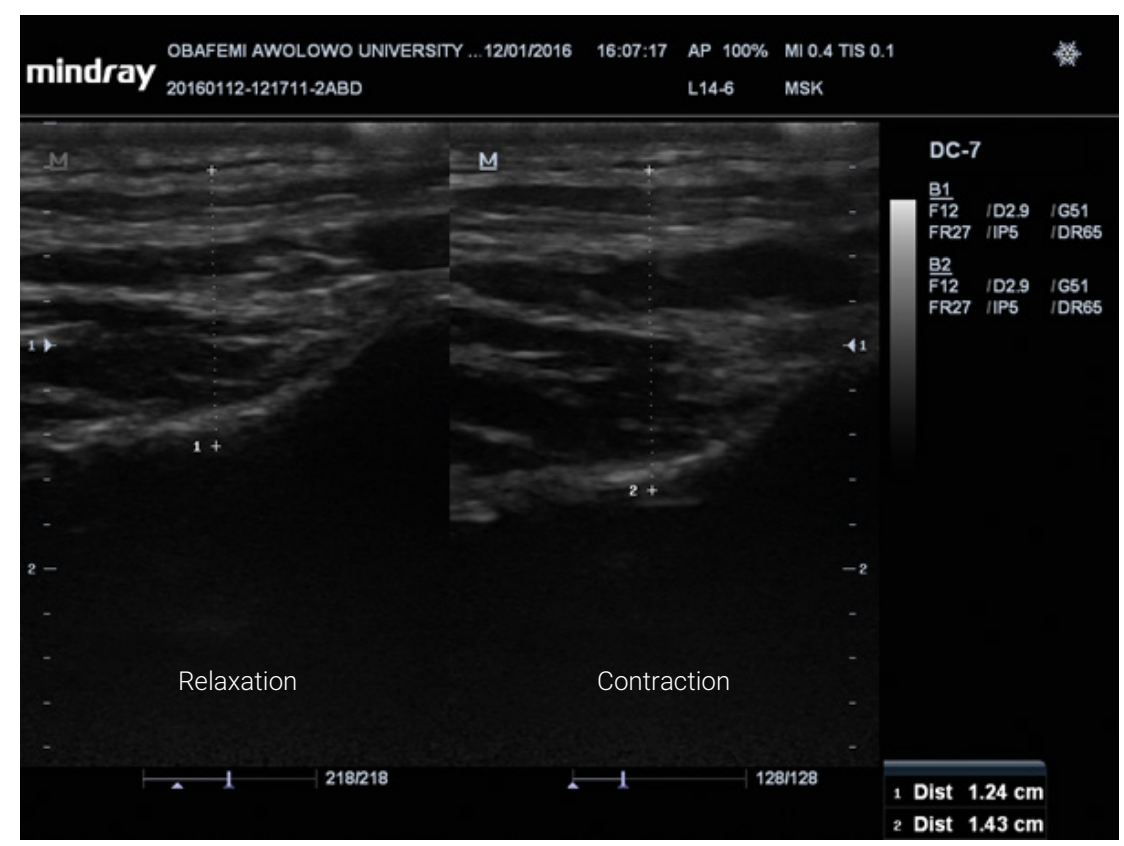

Figure 1. Ultrasonographic image of relaxed and contracted masseter muscle. The callipers indicate the points at which the muscle thickness was taken. The superficial cursor indicates the surface of the transducer, while the deep cursor indicates the mandibular ramus.

In conclusion, the masseter muscle was thicker during contraction than during the relaxation phase. In addition, the muscle was thicker on the habitual side of mastication. Additionally, there was a direct relationship between masseter muscle thickness and overbite variations, that is, as the overbite value increased, the muscle thickness also increased.

\section{References}

1. Vreeke M1, Langenbach GE, Korfage JA, Zentner A, Grünheid T. The masticatory system under varying functional load. Part 1: Structural adaptation of rabbit jaw muscles to reduced masticatory load. Eur J Orthod. 2011 Aug;33(4):359-64. doi: 10.1093/ejo/cjq083.

2. Kiliaridis S, Georgiakaki I, Katsars C. Masseter muscle thickness and maxillary dental arch width. Eur J Orthod. 2003 Jun;25(3):259-63.

3. Pepicelli A, Woods M, Briggs C. The mandibular muscles and their importance in orthodontics: A contemporary review. Am J Orthod Dentofacial Orthop. 2005 Dec;128(6):774-80.

4. Chan HJ, Woods M, Stellac D. Mandibular muscle morphology in children with different vertical facial patterns: A 3-dimensional computed tomography study. Am J Orthod Dentofacial Orthop. 2008 Jan;133(1):10.e1-13. doi: 10.1016/j.ajodo.2007.05.013.

5. Raadsheer MC, Kiliaridis S, Van Eijden TM, Van Ginkel FC, Prahl-Andersen B. Masseter muscle thickness in growing individuals and its relation to facial morphology. Arch Oral Biol. 1996 Apr;41(4):323-32.

6. Profitt WR, Fields HW, Saver DM. Contemporary Orthodontics. $4^{\text {th }}$ ed. Mosby; 2007. p. 130-61.

7. Kiliaridis S, Katsars C. The effects of myotonic dystrophy and Duchenne muscular dystrophy on orofacial and dentofacial morphology. Acta Odontol Scand. 1998 Dec;56(6):369-74. 
8. Hunt NP, Shah R, Sinanan A, Lewis M. Muscling in on malocclusions: Current concepts on the role of muscles in the aetology and treatment of malocclusion. J Orthod. 2006 Sep;33(3):187-97.

9. Opdebeeck H, Bell WH. The short face syndrome. Am J Orthod. 1978 May;73(5):499-511.

10. Schendel SA, Eisenfeld J, Bell WH, Epker BN, Mishelevich DJ. The long face syndrome: Vertical maxillary excess. Am J Orthod. 1976 Oct; $70(4): 398-408$.

11. Weijs W A, Hillen B. Relationships between masticatory muscle Cross-section and skull shape. J Dent Res. 1984 Sep;63(9):1154-7

12. Hannam A G, Wood W W. Relationships between the size and spatial morphology of human masseter and medial pterygid muscles, the craniofacial skeleton, and jaw biomechanics. Am J Phys Anthropol. 1989 Dec;80(4):429-45.

13. Serra MD, Gavião MBD, Uchôa MNDS. The use of ultrasound in the investigation of the muscles of mastication. Ultrasound Med Biol. 2008 Dec;34(12):1875-84. doi: 10.1016/j.ultrasmedbio.2008.05.009.

14. Raadsheer MC, van Eijden TM, van Spronsen PH, van Ginkel FC, Kiliaridis S, Prahl-Andersen B. A comparison of human masseter muscle thickness measured by ultrasonography and magnetic resonance imaging. Arch Oral Biol. 1994 Dec;39(12):1079-84.

15. Benington PC, Gardener JE, Hunt NP. Masseter muscle volume measured using ultrasonography and its relationship with facial morphology. Eur J Orthod. 1999 Dec;21(6):659-70.

16. Eng J. Sample sze estimation: How many individuals should be studied. Radiology. 2003 May;227(2):309-13.

17. Profitt WR, Fields HW, Saver DM. Contemporary Orthodontics. $4^{\text {th }}$ ed. Mosby; 2007. p. 3-23.

18. Kiliaridis S, Kälebo P. Masseter muscle thickness measured by ultrasonography and its relation to facial morphology. J Dent Res. 1991 Sep;70(9):1262-5.

19. Egwu OA, Njoku CO, Enwunonu EO, Koha UU, Eteudo AN, Mgbachi CE. Assessment of masseter muscle thickness in an adult nigerian population: an ultrasound based study. Int J Biomed Res. 2012;3(3):143-6.

20. Satıroglu F, Arun T, Isik F. Comparative data on facial morphology and muscle thickness using ultrasonography. Eur J Orthod. 2005 Dec;27(6):562-7.

21. Kubota M, Nakan H, Sanjo I, Satoh K, Sanjo T, Kamegai T, et al. Maxillofacial morphology and masseter muscle thickness in adults. Eur J Orthod. 1998 Oct;20(5):535-42.

22. Rani S, Ravi MS. Masseter muscle thickness in different skeletal morphology: An ultrasonographic study. Indian J Dent Res. 2010 Jul-Sep;21(3):402-7.

23. Bakke M, Tuxen A, Vilmann P, Jensen BR, Vilmann A, Toft M. Ultrasound image of human masseter muscle related to bite force,electromyography, facial morphology and occlusal factors. Scand J Dent Res. 1992 Jun;100(3):164-71.

24. Raadsheer MC, van Eijden TM, van Ginkel FC, Prahl-Andersen B. Contribution of jaw muscle size and craniofacial morphology to human bite force magnitude. J Dent Res. 1999 Jan;78(1):31-42.

25. He T, Olsson S, Daugaard JR. Functional influence of masticatory muscles on the fibre characteristics and capillary distribution in growing ferrets (Mustela putonusfuro)-a histochemical analysis. Arch Oral Biol. 2004 Dec;49(12):983-9.

26. Kiliaridis S, Mahboubi PH, Raadsheer MC, Katsaros C. Ultrasonographic thickness of the masseter muscle in growing individuals with unilateral crossbite. Angle Orthod. 2007 Jul;77(4):607-11.

27. Marquezin MC, Andrade AS, Gameiro GH, Gaviao MB,Benington PMC. Evaluation of sexual dimorphismand the relationship between craniofacial, dental arch and masseter muscle characteristics in mixed dentition stage. Rev CEFAC. 2014 Jul-Aug; 16(4):1231-8. doi: 10.1590/1982-021620149613. 
28. Pereira LJ, Gaviao MBD, Bonjardim LR, Castelo PM, van Der Bilt A. Muscle thickness, bite force, and cranio-facial dimensions in adolescents with signs and symptoms of temporomandibular dysfunction. Eur J Orthod. 2007 Feb;29(1):72-8.

29. Van Spronsen PH, Weijs WA, Valk J, Prahl-Andersen B, Van Ginkel FC. A comparison of jaw muscle cross-sections of long-face and normal adults. J Dent Res. 1992 Jun;71(6):1279-85.

30. Rasheed SA, Munshi AK. Electromyographic and ultrasonographic evaluation of the circum-oral musculature in children. J Clin Pediatr Dent. 1996 Summer;20(4):305-11.

31. Hannam AG, McMillan AS. Internal Organization in the Human Jaw Muscles. Crit Rev Oral Biol Med. 1994;5(1):55-89. 